\title{
Evaluation of Teaching Effect and Application of Project Teaching in Costume Graphics Course
}

\author{
Chunhui Zhou \\ College Fine Arts, China West Normal University, Nanchong 637009, China \\ 22446818@qq.com
}

\begin{abstract}
Project teaching method is introduced into the costume graphics course ac- cording to the demand of talents in modern garment industry. The practical and innovative thinking ability, integration capability of interdisciplinary knowledge, market awareness and career planning ability of the students were all improved obviously through application and practice of real enterprise project, simulation project and competition projects, which provides a certain reference value for the teaching of costume graphics course.
\end{abstract}

Keywords: Costume graphics; Project teaching; Practice and application; Effectiveness evaluation.

\section{服饰图案课程项目教学法的应用与效果评价}

\author{
周春晖 \\ 西华师范大学美术学院, 南充 中国
}

摘要: 根据现代服装行业对人才的需求, 将项目教学法引入到服饰图案课程中, 通过真实企 业项目、模拟项目、大赛项目的应用与实践, 学生的实践能力与创新思维能力, 跨学科知识 的整合能力, 市场意识与职业规划能力等都得到了明显提高, 对服饰图案课程的教学提供了 一定的参考价值。

关键词: 服饰图案; 项目教学; 应用与实践; 效果评价

\section{1. 前言}

党的十八大明确提出了深化教育体制综合改革, 推动高等教育内涵式发展, 深入推进产 教融合, 校企合作, 建立现代职业教育体系的要求。当前纺织行业经济总量增长由原来的高 速逐渐向中速转变, 企业下行压力比较大, 综合成本在上升, 但 “一带一路” 战略实施或给 纺织行业带来了新契机。现在服装企业已经从追求款式的变化转变为服装材质、功能和图案 的变化, 随着信息化和电脑技术高速发展, 为服饰图案的设计和印染带来了更多的便利。当 今社会需要的是专业知识全面, 综合素质较高的服装设计师, 而且服饰图案设计师在纺织服 装行业有了广阔的发展空间。

\section{2. 服饰图案课程教学中运用项目教学法的意义}

项目教学法（Project-based Learning），也叫专题教学或基于项目的学习，是指师生共同 实施一个完整的项目而进行的教学活动。项目教学是建立在建构主义和情景学习理论基础之 上以体现行动导向教育理念的教学方法。项目教学是通过组织学生真实参加企业项目的设计、 实施、评价等过程, 在教师主持下, 让学生在完成项目过程获得专业知识和技能, 从而完成 教学目标。学生在这个过程中锻炼实践动手能力、自主学习能力、职业岗位能力、综合应用 能力以及团队协作能力, 是一种探索创新的新型教学模式。

服饰图案设计课程作为服装与服饰设计本科专业中一门专业基础课程，也是一门将理论 与实践、市场与艺术、工艺与设计融合在一起的综合性极强的课程。项目教学法在其他专业 
课程改革实践表明, 该方法能有效改革传统教学上存在的教师主导, 学生实践能力和创新能 力不足等教学问题, 能促进人才培养模式改革与创新, 满足当前社会发展对创新创业人才的 迫切需求。

\section{3. 服饰图案课程项目教学法的应用}

\section{1 实施步骤}

笔者在西华师范大学美术学院服装与服饰设计专业服饰图案课程中进行了项目教学法的 教学实践。根据教学法的教学思路, 结合课程教学目标和学生的实际情况, 服饰图案课程项 目教学法的实施主要分为以下五个步骤:

3. 1.1 确定项目

教学项目的选择应该根据教学目标有针对性的选择，根据教学内容不同板块，设计不同 项目与之结合, 解决教学目标中所需掌握的综合知识与技能; 另外, 选择项目时还要以学生 的个体特性为依据, 形成层次化和差异化的项目教学。服饰图案课程项目教学分阶段, 分层 次采用了真实的企业项目、工作室项目、大赛项目和虚拟项目作为项目教学的特色。

\section{1.2 任务分解}

项目任务分解是指对一个完整的教学目标或教学项目分解成若干个具体教学任务的过 程。真实的企业项目由专业教师与企业管理层一起完成, 企业管理层经验丰富, 对每个子任 务的难度和所需时间比较熟悉, 能够合理的控制项目的进度, 因此在教学项目的分解中将企 业管理层参与进来更有助于项目的有序开展。

\subsection{3制定计划}

教学项目的任务分解完成后, 需要对各个子项目制定详细的教学计划。制定计划的第一 步是根据各个子项目的难易程度和学校教学计划中的总课时量来综合考虑, 合理分配各个子 项目的具体课时。根据不同子项目的任务目标与班上同学的实践能力来分组, 并为每个小组 任命一个小组长。在分组的过程中要充分考虑各小组的实力相当, 小组成员各具特色, 能力 互补, 具有共同协作的潜力, 才能很好地完成项目任务。小组成员分组结束后, 再由每组的 小组长根据成员的特点来安排合适的任务, 小组中角色的定位和工作任务的分配要尽可能发 挥各成员的特长。完成以上步骤之后, 各个小组在老师的指导下制定详细的项目计划书, 每 个小组成员都严格按照项目计划开展任务。

3. 1.4 项目实施

在项目实施过程中，教师应随时关注各小组的项目进展情况，对项目执行过程中遇到的 难题要及时给予指导和建议。各小组成员之间要团结协作, 碰到难题及时沟通, 经常向老师 汇报项目进度。各小组之间也要多多交流, 对于好的方法要相互学习和借鉴。教师和企业专 家组成指导团队, 相互之间紧密沟通、团结协作, 一起对项目的进展情况进行指导, 确保项 目在规定时间按质按量的完成。

\section{1.5 学习评估}

项目任务完成后, 根据项目完成情况、质量和企业接受度来衡量学生的学习效果, 由教 师或企业、学习小组与个人一起对学生多种能力进行综合评价。服饰图案教学项目效果的评 价包括两部分内容: 一部分是对各小组项目完成效果的评价, 另一部分就是教学效果的评价。 在评价过程中我们采用形成性评价与总结性评价相结合的方法进行, 评价人员由内部人员 (专 业教师和学生) 和外部人员（企业专家）相结合组成。

3.2 真实的企业项目案例

西华师大美术学院服装与服饰设计专业服饰图案课程的项目教学法案例采用真实的企业 项目、工作室项目、大赛项目和虚拟项目作为项目教学的特色, 下面就一例真实的企业项目 来分析具体教学过程:

该项目是与南充六合（集团）有限公司进行合作，在2014级服装与服饰设计专业的服饰 图案课程中进行了该项目的教学实践。项目任务为: 根据企业特色, 结合流行趋势, 以“花 
卉” 为主题进行服装图案的设计, 并进行服装款式的研发, 掌握服饰图案从设计到产品实现 的整个工艺流程。该课程安排在第二学期 5-9周, 共 80 学时, 参与教学实践的学生人数为 21 人。此次项目教学的设计与实施是在服饰图案理论教学模块结束后进行的, 学生已经基本了 解了服饰图案的概念、特征、类型和设计原理等, 此次项目实施总课时为48课时, 分三周时 间完成。根据项目任务, 教师把学生分成了 3 个小组, 每组由小组内部推选一名小组长, 来开 展服饰图案设计的项目实践活动。

项目任务的实施分为以下几个步骤进行, 首先是由教师以项目主持人的身份与学生一起 讨论本次项目的主题, 介绍该服装企业文化背景, 分析项目内容和所需达到的教学目标, 公 布活动规则以及评价标准。接下来组织学生进行市场调查, 包括参观企业, 并由企业负责人 为学生介绍自己品牌的风格特征、消费者定位, 带领学生参观此次项目任务的整个流程; 到 各大商场对服装品牌进行市场调查, 对服饰图案的风格、材质、色彩搭配、工艺手法等进行 归纳、提炼, 以调查分析报告的形式呈现出来。根据市场调查收集的信息和资料, 各小组绘 制设计草图, 提出可行的解决方案, 再在小组间进行交流, 学生根据老师和同学们提出的问 题进行讨论和分析, 并对自己的方案进行修改和调整, 确定出最终方案。将完整的方案包括 效果图、设计说明、工艺手法说明等与老师进行交流, 老师给出建议。项目方案确定后, 各 组成员在老师的带领下将教学场地转移到六合 (集团) 有限公司, 根据各个小组的设计方案, 由企业负责人验证各组所设计的服饰图案是否符合企业的生产工艺要求, 如不符合要及时修 改和调整。接下来了解服饰图案从纸样-描稿-制版-调色-印刷一后处理等工艺流程, 各类染色 方法、各种染料性质、各种印花方法以及图案设计与制版、调色、印花之间的关系等。并在 企业技术人员的指导下完成图案的印染、刺绣等工艺流程, 企业相关人员给予协助完成服装 系列作品。

最后进行项目任务的评价, 该项目任务的评价由形成性评价和总结性评价、企业专家和 专业教师评价相结合, 首先, 每个小组派一名代表用PPT的形式对自己的作品进行阐述, 并总 结优点与不足; 然后小组之间相互评价; 最后由专家组成员和教师对每组作品进行点评, 并 提出改进措施, 最后形成书面的评价报告。

\section{4. 项目教学法效果评价}

通过对我校服装与服饰设计专业三个年级共121名学生在服饰图案课程中实施项目教学, 与传统教学法相比较, 学生的各项综合能力有了一定提高, 特别是表现在以下几个方面:

4.1 学生的实践能力与创新思维能力显著增强

服饰图案课程通过采用项目教学法, 学生了解了服饰图案从设计到产品实现的生产流程 以及掌握各种工艺制作手法和设备的操作, 实践性极强, 学以致用, 动手实践能力大大提高; 学生在完成产品的过程中, 面对项目实施中的难题, 努力探索, 积极思考, 吸收新知识来解 决问题, 对所学内容和学习过程进行反思, 学生的创新思维能力也显著增强。

4.2 学生跨学科知识的整合能力明显提高

项目教学法是把教学内容放在一个完整的任务里进行, 在完成整个项目的过程中, 学生 需了解多门专业课程的知识才能有序的开展。比如要完成一个服饰图案设计的项目, 就需要 把服装设计基础, 美学原理, 计算机服装设计, 服装手工艺技术等多门学科知识结合在一起, 学生务必进行主动学习, 老师做必要的知识补充。学生在项目实施的过程中自主进行知识的 整合和建构, 促进了学生的跨学科知识的整合能力。

4.3 学生的市场意识与职业规划能力有了一定提升

从刚开始老师对于项目的分析到进行相关产品的市场调查, 从草图的绘制到图案正稿的 完成, 从产品的实现到接受市场的检验, 这其中的每一个步骤都与市场紧密结合, 也让学生 时刻关注流行资讯，培养敏锐的市场洞察力，为今后就业及时与市场接轨打下坚实的基础。 学生在完成任务的同时也逐渐清楚自己在专业上所擅长的领域是哪一方面, 及时进行自己的 职业规划。 


\section{5. 结论}

服饰图案作为服装与服饰设计专业的一门基础课程, 引入项目教学法进行教学, 也是响 应高等学校创新创业教育改革的号召, 实践证明, 该课程运用项目教学法进行教学是可行的, 并取得了一定的成效。学生的学习积极性明显提高, 市场意识和实践动手能力显著增强, 学 生分析解决问题的能力、语言沟通能力、团结协作能力和组织协调能力得到了进一步提升。 当然, 服饰图案课程教学内容较多, 项目教学法虽然有其独特的优势, 但也有不足之处, 比 如项目教学法耗时较长, 对教师的要求比较高等。在服饰图案课程的教学中, 还应该与其他 的教学法相结合, 如启发式教学法、案例教学法等, 根据不同的教学内容和知识结构, 选择 不同的教学方法, 才能取得更好的教学效果。

\section{References}

[1] George Lueas Educational Foundation, http://www.edutopia.org.

[2] Xunxin Wu, Xiaoli Yuan. Application of Project Teaching in Costume Graphics Course [J]. De sign, 2014, (3): 185-186.

[3] Guohong Zhou. Primary Investigation of Application of Project Teaching in the Specialty of Co mputer-aided Art Design of Secondary Vocational School [D]. Beijing: Capital Normal Univers ity, 2006:25.

[4] Huifang Wang. Teaching Reflection of Costume Graphics Course [J]. Art \&Design, 2007, (8): 106-107.

[5] Min Zeng. Application of Project Teaching Model in the Secondary Vocational Clothing Profes sional [D]. Chengdu: Sichuan Normal University, 2013.

[6] Yuping Deng. Analysis on Teaching Mode in Clothing Professional Based on Project Teaching [J]. Arts Exploration, 2011, (3): 73-74. 